DOI: https://doi.org/10.24867/09GI09Milodanovic

\title{
UNAPREĐENJE KVALITETA PROIZVEDENIH PLOČICA PREDUZEĆA „POLET KERAMIKA“"
}

\section{IMPROVEMENT OF THE QUALITY OF POLET CERAMICS TILES}

\section{Sonja Milodanović, Fakultet tehničkih nauka, Novi Sad}

\section{Oblast: INDUSTRIJSKO INŽENJERSTVO}

Kratak sadržaj - U radu je na osnovu snimka stanja izvř̌ena analiza uzroka nastanka glavnog problema procesa proizvodnje $i$ službe kvaliteta, a to je loš kvalitet proizvedenih pločica u preduzeću „Polet keramika“ $i$ na osnovu izvršenog ocenjivanja uzroka, primenom FMEA analize došli smo do najktitičnijih uzroka za koje su u radu preporučene mere unapređenja, čija primena bi doprinela rešavanju postavljenog problema.

Ključne reči: Logistika, Proizvodnja, Unapređenje kvaliteta

\begin{abstract}
The paper also analyzes the cause of the main problem in the production process and quality assurance, which is the poor quality of tiles produced in the company "Polet Ceramics" and based on the performed cause assessment, using FMEA analysis we have come to the most critical causes for which improvement measures are recommended and whose implementation would contribute to solving the problem.
\end{abstract}

Keywords: Logistics, Production, Quality Improvement

\section{UVOD}

Svako preduzeće ukoliko želi da opstane na tržištu i obezbedi svoj daljnji razvoj mora da prati uslove tržišta kao i konkurenciju.

Kako bi uspešno pratilo najnovije uslove tržišta kao i uslove u vidu kvaliteta i promena među sličnim proizvodima koje nameću srodne konkurentske firme, mora konstantno da unapređuje svoje poslovanje, da obezbeđuje određen, prepoznatljiv kvalitet svojih proizvoda i da održava kvalitetne odnose sa kupcima.

$\mathrm{U}$ ovom radu u teorijskom delu predstavljene su funkcije logistike, proizvodnje i naznačena je važnost upravljanja kvalitetom. U ostatku rada susrećemo se sa trenutnim problemima u radu pomenutih funkcija, kao i njihovim uzrocima ali i predlozima za njihovo rešavanje.

\section{FUNKCIJA PROIZVODNJE}

Proizvodnja je svrsishodna ljudska delatnost $u$ kojoj se određeni skup resursa - inputa, transformiše u određene proizvode autpute koji služe zadovoljenju ljudskih potreba.

\section{NAPOMENA:}

Ovaj rad proistekao je iz master rada čiji mentor je bio dr Stevan Milosavljević, red.prof.
Proizvodnja predstavlja najvažniju fazu $u$ procesu društvene reprodukcije, jer je ona materijalna osnova za funkcionisanje ostalih društvenih procesa $\mathrm{i}$ aktivnosti [1].

\subsection{Tipovi proizvodnje}

U organizacijskom smislu a prema veličini i vrsti asortimana proizvodnja se deli na tri osnovna tipa:

- pojedinačna proizvodnja,

- serijska proizvodnja,

- masovna proizvodnja.

Pojedinačna proizvodnja predstavlja proizvodnju manjih količina nekih unikatnih proizvoda po narudžbini.

Serijska proizvodnja predstavlja proizvodnju proizvoda u određenom broju pojedinačnih serija, gde u jednoj seriji se proizvode veće količine istih ili sličnih proizvoda.

Masovna proizvodnja je kontinualna, automatizovana i predstavlja proizvodnju velikih količina proizvoda [2].

\section{UPRAVLJANJE KVALITETOM}

Preduzeće koje želi da ispuni želje kupaca mora da ima implementiran sistem upravljanja kvalitetom.

Sistem kvaliteta predstavlja promene $\mathrm{u}$ organizaciji, dokumentaciji, procesima i motivaciji zaposlenih, u svim funkcijama i delovima preduzeća. Kvalitet poslovanja podrazumeva menadžment pristup, odnosno upravljanje kvalitetom poslovanja. preduzeća, identifikovano kroz poštovanje međunarodnih standarda kvaliteta [3].

\section{PODACI O ORGANIZACIJI}

Fabrika keramičkih pločica „Polet keramika“ d.o.o., smeštena u ulici Železnička 13 u Novom Bečeju, osnovana je 1980. godine u Novom Bečeju. Danas "Polet keramika" posluje u okviru poslovnog sistema Nexe Grupe. Fabrika se bavi proizvodnjom podnih, zidnih i fasadnih keramičkih pločica i pratećeih dekorativnih elemenata. Broj zaposlenih: 130. Najznačajniji uzroci koji najviše doprinose stvaranju glavnog problema, a to je loš kvalitet proizvedenih proizvoda.

\subsection{Snimak stanja}

Planirana količina proizvedenih podnih i zidnih pločica na mesečnom nivou iznosi $200.000 \mathrm{~m}^{2}$

Planirani procenat klasa: 


\section{PRVA KLASA $85 \%$}

2. DRUGA KLASA $10 \%$

\section{ROBA SA GREŠKOM 5\%}

Sledi tabelarni prikaz procentualno izraženih proizvedenih količina po klasama na mesečnom nivou.

Tabela 1. Procentualni prikaz proizvedenih klasa po mesecima u 2019. godini

\begin{tabular}{|c|c|c|c|c|}
\hline Redni broj & Mesec & $\begin{array}{c}\text { Prva } \\
\text { klasa u } \\
(\%)\end{array}$ & $\begin{array}{c}\text { Druga } \\
\text { klasa u } \\
(\%)\end{array}$ & $\begin{array}{c}\text { Roba sa } \\
\text { greskom u } \\
(\%)\end{array}$ \\
\hline 1 & Januar & \multicolumn{3}{|c|}{ Nema proizvodnje } \\
\hline 2 & Februar & $80 \%$ & $15 \%$ & $5 \%$ \\
\hline 3 & Mart & $82 \%$ & $13 \%$ & $5 \%$ \\
\hline 4 & April & $79 \%$ & $17 \%$ & $4 \%$ \\
\hline 5 & Maj & $70 \%$ & $23 \%$ & $7 \%$ \\
\hline 6 & Jun & $73 \%$ & $18 \%$ & $9 \%$ \\
\hline 7 & Jul & $58 \%$ & $29 \%$ & $13 \%$ \\
\hline 8 & Avgust & $40 \%$ & $55 \%$ & $5 \%$ \\
\hline 9 & Septembar & $42 \%$ & $54 \%$ & $4 \%$ \\
\hline 10 & Oktobar & $63 \%$ & $32 \%$ & $5 \%$ \\
\hline 11 & Novembar & $55 \%$ & $25 \%$ & $7 \%$ \\
\hline 12 & Decembar & \multicolumn{3}{|c|}{ Nema proizvodnje } \\
\hline $\begin{array}{l}\text { Prosečna } \\
\text { vrednost }\end{array}$ & Godišnje & $64 \%$ & $28 \%$ & $6 \%$ \\
\hline
\end{tabular}

Na osnovu tabele 1. vidimo kako ni jedan mesec u celoj godini poslovanja nije ostvarena planirana količina po klasama, pogotovo količina prve klase. Možemo videti kako posečna vrednost mesečne proivodnje prve klase iznosio samo $64 \%$.

\section{PRIKUPLJANJE PODATAKA I ANALIZA MOGUĆIH UZROKA PROBLEMA}

Primenom FMEA analize ocenićemo svaki od istaknutih uzroka i na osnovu dobijenog RPN faktora uvideti koji su

Tabela 2. Uzroci definisanog problema

\begin{tabular}{|c|c|}
\hline Stare, dotrajale mašine & $\begin{array}{c}\text { Nekorišćenje validnih } \\
\text { procedura za rad }\end{array}$ \\
\hline $\begin{array}{c}\text { Nepostojanje funkcije } \\
\text { održavanja }\end{array}$ & Nemotivisanost zaposlenih \\
\hline $\begin{array}{c}\text { Nepostojanje potrebnih } \\
\text { rezervnih delova }\end{array}$ & Zanemarivanje problema \\
\hline $\begin{array}{c}\text { Česta promena i nedovoljan } \\
\text { broj zaposlenih }\end{array}$ & $\begin{array}{c}\text { Loši odnosi medju } \\
\text { zaposlenima }\end{array}$ \\
\hline $\begin{array}{c}\text { Pojava metala u smesi za } \\
\text { biskvit }\end{array}$ & $\begin{array}{c}\text { Nepostojanje celokupne i } \\
\text { nekorišćenje adekvatne } \\
\text { zaštitne opreme }\end{array}$ \\
\hline $\begin{array}{c}\text { Neadekvatno čišćenje } \\
\text { mašina }\end{array}$ & $\begin{array}{c}\text { Nedostatak potrebne obuke } \\
\text { za rad }\end{array}$ \\
\hline $\begin{array}{c}\text { Nedostatak jasne raspodele } \\
\text { odgovornosti i ovlašćenja } \\
\text { kod zaposlenih }\end{array}$ & $\begin{array}{c}\text { Zapošljavanje nedovoljno } \\
\text { stručnog i nedovoljno } \\
\text { iskusnog kadra }\end{array}$ \\
\hline $\begin{array}{c}\text { Nedostatak proizvoda prve } \\
\text { klase za prodaju }\end{array}$ & Veliki troškovi proizvodnje \\
\hline
\end{tabular}

\subsection{Primena FMEA metode na definisanom problemu}

Numerički prioritet rizika (RPN broj) se jednostavno računa množenjem ocena sva tri faktora. RPN = POSLEDICA $x$ VEROVATNOĆA $x$ DETEKCIJA,

Primenom FMEA analze, izvrsili smo ocenu svih uzoraka na osnovu posledica, verovatnoće i detekcije uzroka.

$\mathrm{Na}$ osnovu dobijenih ocena, množenjem ove tri ocene dobijamo RPN faktor za svaku od posledica.

$\mathrm{Na}$ osnovu dobijenih rezultata, sprovedenom FMEA analizom, dolazimo do podataka koja to 3 različita uzroka ispitanog problema imaju najviši RPN faktor.

Uzroci sa najvećim RPN faktorom:

1. Nepostojanje funkcije održavanja 125 RPN

2. Nekorišćenje validnih procedura za rad 125 RPN

3. Pojava metala u smesi za biskvit $125 \mathrm{RPN}$

\section{DEFINISANJE MERA POBOLJŠANJA}

U nastavku će biti predložene mere za poboljšanje, čijom primenom bismo mogli poboljšati kvalitet krajnjeg proizvoda.

\section{1 Formiranje službe održavanja}

\section{Projektovanje sistema održavanja}

U ovom preduzeću potrebno je oformiti službu održavanja čiji rad bi se zasnivao na metodologiji održavanja prema pouzdanosti. Ovaj način rada službe održavanja, nakon određenog vremena uspešnog poslovanja omogućio bi pouzdaniji i bezbedniji rad postrojenja, izvršenje zadataka uz što manje troškove, manje troškove samog održavanja ali i saniranja neizbežno nastalih otkaza.

Kako bi obezbedili rad ove službe pre svega potrebno je preurediti određeni deo prostora tj. broj prostorija u samoj zgradi preduzeća, u koje bismo smestili zaposleni ove funkcije. Na osnovu uvida $u$ izgled i raspored sedišta funkcija $\mathrm{u}$ preduzeću, uviđeno je da prostora za ovako nešto ima, a kako bi ova služba efikasnije radila potrebno je, a i moguće, smestiti je baš u prostorije koje se nalaze u neposrednoj blizini samog proizvodnog pogona.

Prostorije je potrebno okrečiti, nabaviti nove radne stolove, stolice, računare, kao i ostali propratni kancelarijski materijal.

Potrebno je izdati oglas za potražnju stručnih, kvalifikovanih i iskusnih osoba za rad u službi održavanja na određenim pozicijama.

* Potrebne pozicije: Rukovodilac poslova tehničkog održavanja, Inženjer tehničkog održavanja i održavanja uređaja i opreme, Tehničar tehničkog održavanja i održavanja uređaja i opreme, i Majstor održavanja (domar).

$\mathrm{Na}$ osnovu toga vidimo da bi broj zaposlenih u novooformljenoj službi održavanja bio 4. Pre početka rada funkcije tj. Primene samih aktivnosti održavanja neophodno je odrediti skup postupaka i aktivnosti koji će se tokom vremena sprovoditi na tehničkim sistemima, mašinama i opremi u cilju sprečavanja nastanka otkaza ali i njihovog otklanjanja. 
Predstavljanje osnovnih zadataka funkcije održavanja:

1. Osnovno održavanje

2. Nadzor

3. Pregled stanja postrojenja, oprema i mašina

4. Popravke

5. Inovacije - poboljšavanje rada tehničkog sistema i njegovog stanja.

$\mathrm{Na}$ osnovu izvršene finansijske analize isplativosti za formiranje službe održavanja, kao najisplativiju opciju za primenu ove mere odabrali smo teću opciju.

Treća opcija bila bi da se preurede prostorije, nabavi potrebna kancelarijska oprema i materijali , kupe potrebni softveri za rad, zaposle delimično stručno osoblje tako da bi jedna osoba od troje zaposlenih imala obuku jer bi bila bez dodatnog radnog iskustva. Tada bi početni troškovi bili $7100 €$, a mesečni troškovi plata $3350 €$.

Godišnji trošak rada ove službe iznosio bi: $7100 €+12$ meseci $* 3350 €=47300 €$, dok bi trošak primene ostlih opcija bio mnogo veći.

\section{2 Izrada i korišćenje novih procedura za rad}

Nekorišćenje procedura za rad na radnim mestima predstavlja problem jer se na ovaj način češće događaju greške prilikom rada. U ovom slučaju nastaju greške u službi kvaliteta kao i tokom obavljanja poslova u procesu proizvodnje, i ove greške utiču na kvalitet krajnjeg proizvoda, negativno. Zato je veoma bitno koristiti ažurirane procedure tokom svakodnevnog poslovanja, i na taj način izbeći mogućnost nastanka ovakvih grešaka. Preporuka je uraditi detaljan pregled procedcura za rad i ažuritati zastarele metode rada koje se više ne koriste, formiranjem novih procedura.

Predlog je izrada nove procedure za izradu probnih pločica. I uvođenju obaveznog korišćenja ove procedure prilikom rada. Probne pločice se prave u internoj laboratoriji preduzeća i od dobijenih pločica i njihovih karakretistika zavisi koja vrsta smese za biskvit će se koristiti u proizvodnji pločica.

Znamo da se struktura i smesa zidnih i podnih pločica razlikuje. Tako da se ovaj postupak radi duplo, za dobijanje zidnih probnih plocica i za dobijanje podnih probnih pločica. Iako je postupak sličan razlikuju se početne kombinacije smesa kao i njihovo procentualno učešće u smesi.

Ova procedura je neophodna, kao i njeno obavezno korišćenje jer je ovaj postupak veoma važan, od njega direktno zavisi kvalitet dobijenih pločica u samom procesu proizvodnje.

Sve ovo radi se kako bi se došlo do informacija koja od korišćenih masa za dobijanje pločica ima najbolje karakretistike. Na ovaj način uvidi se koja je masa najbolja za proizvodnju pločica.

$\mathrm{Na}$ osnovu izvršene finansijske analize isplativosti za izradu i korišćenje novih procedura došlo se do sledećeg zaključka.

Sprovođenje druge preporučene mere poboljšanja koja predstavlja izradu novih procedura za rad u preduzeću "Polet keramika" pre svega u službi kvaliteta, kao i obavezno korišćenje procedura u toku procesa rada, jeste mera koja ne iziskuje skoro nikakva novčana ulaganja.
Tačnije odnosi se na korišćenje čistog minulog rada samih zaposlenh koji bi mogli izraditi određene procedure unutar preduzeća.

\subsection{Nabavka i postavljanje magneta u proizvodne mašine}

Plan nabavke $i$ postavljanja magneta u mašine za proizvodnju

Potrebno je izvršiti pregled mašina i uvideti na kojim mestima magneti postoje i mogu se još uvek koristiti (primenom redovnog i odgovornog čišćenja), uvideti koji su dotrajali i moraju se zameniti, kao i na kojim mestima magneti nedostaju, i odrediti broj magneta potrebnih za nabavku.

Nakon utvrđivanja broja magneta potrebno je utvrditi tačan naziv i oznaku svakog od magneta, kako bi se ovi podaci mogli proslediti službi nabavke, i kako bi ona raspisala konkurs za nabavku i nabavila potreban broj magneta po minimalnoj ceni.

Nakon nabavke magneta potrebno je izvršiti njihovo postavljanje. Ovo je najbolje izvršiti u toku procesa remonta.

Nakon postavljanja magneta potrebno je odrediti osobu iz preduzeća koja bi svojim obavezama pripisila i praćenje rada mašina nakon postavljanja magneta. Praćenje proizvodnih količina iz svake od klasa. Poređenje dobijenih rezultata sa prethodnim rezultatima proizvedenih količina po klasama. Potrebno je pratiti zasićenje magneta magnetnim česticama iz smese i proračunati potreban vremenski period za zasićenje magneta magnetnim česticama, kako bi se utvrdio vremenski interval čišćenja magneta od nagomilanih čestica.

Veoma je bitno da se magneti čiste na tačno i jasno definisan način ali i određeni vremenski period i to pre nego što do prezasićenja i dođe.

Ukoliko se dopusti prezasićenje magneta pre postupka čišćenja desiće se da određena količina proizvedenog biskvita će ipak sadržati veće količine metalnih čestića nego što je to dozvoljeno za ovakvu vrstu smese i opet će kvalitet proizvod biti narušen. Zato je bitno precizno i odgovorno odrediti interval čišćenja magneta.

Čiščenje magneta bi bio posao osobe koja bi se morala barem na neki način osbosobiti za rad kako bi taj deo posla bio završen temeljno i odgovorno jer od njega zavisi u velikoj meri kvalitet krajnjeg proizvoda.

Moguće je da to bude jedna od zaposlenih osoba $u$ preduzeću, ili neko sa strane $u$ vidu povremeno unajmljene osobe za obavljanje određene vrste posla po jasno definisanim pravilima.

$\mathrm{Na}$ osnovu izvršene finansijske analize isplativosti za postavljanje magneta $\mathrm{u}$ proizvodne mašine, kao najisplativiju opciju primene odabrali smo treću opciju.

Treća opcija bila bi nabavka magneta za $2500 €$, i izbegavanje troškova postavljanja i održavanja. Jer bi ove poslove mogao obavljati neko od već zaposlenih.

Finansijski troškovi ukupno: $2500 €$. 


\section{ZAKLJUČAK}

Veoma je važno uvideti koliko problemi koji nastaju tokom rada jedne funkcije mogu ozbiljno ugroziti rad ostalih funkcija u preduzeću. U ovom slučaju pošto se radi o proizvodnom preduzeću, problem u procesu proizvodnje se u velikoj meri odražava na rad ostalih funkcija, kao što je rad službe kvaliteta, službe prodaje, i održavanja. Zbog toga je ovaj problem proizvodnje neophodno što pre rešiti. Često je problem već toliko eskalirao da njegovo rešavanje zahteva vremena, ali pre svega mnogo rada i truda kako bi se bilo kakvo poboljšanje moglo uspostaviti.

Dve od tri predložene mere, na osnovu finansijske analize mogu se primeniti na što ekonomičniji način i na taj način obezbediti rešavanje problema uz minimalne troškove primena mera poboljšanja. Dok jedna predstavlja ulaganje samo minulog rada samih zaposleni, bez dodatnih troškova.

Napomena: Odricanje od odgovornosti

Podaci u ovom radu predstavljaju samo presek stanja u datom trenutku, i mogu biti delimično izmenjeni i nerealno prikazani.

\section{LITERATURA}

[1] Prof. Dr. D. Šoškić 1984, Ekonomska enciklopedija I; „Savremena adninstracija“ Beograd.

[2] Dr. Ž. Radosavljević i Dr. R. Tomić; 2007, Menadžment u modernom biznisu; Univerzitet „Braća Karić"; Beograd.

[3] (26.01.2020.) http://www.maturski.org - Seminarski rad: Upravljanje kvalitetom .

\section{Kratka biografija:}

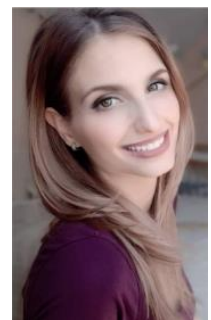

Sonja Milodanović rođena u Novom Sadu 1993. god. Master rad na Fakultetu tehničkih nauka iz oblasti Industrijskog inženjerstva odbranila je 2020.god.

kontakt: sonja.ivanisevic11@gmail.com 